\title{
Neurological impairment of the monozygotic twins with congenital infection presumed by Zika virus: Case report
}

Ana Karina Rocha Hora Mendonça 1

Sonia Oliveira Lima 2

1,2 Universidade Tiradentes. Av. Murilo Dantas, 300. Bairro Farolândia. Aracaju, SE, Brasil. CEP: 49032-490. E-mail: anakarinahora@hotmail.com

\begin{abstract}
Introduction: the increase in the incidence of congenital microcephaly in Brazil has been associated to the Zika virus outbreak. This case report aimed to describe the neurological impairment of monozygotic twins presumably due to an intrauterine infection by Zika virus during the Brazilian outbreak in 2015.

Case description: The monozygotic twins born at term with severe congenital microcephaly were taken to the Outpatient Pediatric Service of a University Hospital. The 17-yearold mother, primigravida, lives in the Northeast region of Brazil, has a normal body mass index, no family history of microcephaly, no clinical history of viral diseases, or exposure to drugs and/or radiation during pregnancy. Serological tests for toxoplasmosis, rubella, syphilis, cytomegalovirus and HIV were negative at the prenatal evaluation and the obstetrical ultrasounds showed a monochorionic, diamniotic twin pregnancy without any evidence of neurological abnormalities. In the post-natal, the imaging of the skull,was evidenced of a great neurological impairment in one of the twins, who, in addition to presenting cerebral calcifications, gliosis and subependymal cysts, also had ventriculomegaly with hydrocephalus of supratentorial predominance and more pronounced cerebral atrophy compared to the other twin. Both presented delayed neuropsychomotor development.

Discussion: distinct neurological alterations in the monochorionic twins with an infection presumed by Zika virus may raise the hypothesis of the existence of predisposing factors or protection against this viral agent.
\end{abstract}

Key words Arbovirus infections, Microcephaly, Twins 


\section{Introduction}

In Brazil, since 2015, an unexpected increase in children born with a diagnosis of microcephaly, especially in the Northeast region was observed and at this time coincided with a period of confirmation of autochthonous transmission of fever by Zika virus (ZIKV) in the Country. ${ }_{1}$ The relationship between microcephaly and neonatal neurological syndromes with congenital ZIKV infection is well established and recognized in Brazil, as well as in ten other countries and territories, including French Polynesia, Colombia, Panama and Martinique. ${ }^{2}$

The increase in the number of cases of congenital microcephaly in Pernambuco and other Brazilian states in the Northeast made the Ministry of Health announce a national public health emergency on November 11, 2015. Subsequently, in February 2016, as a result of the dissemination to other American countries, the World Health Organization declared that the ZIKV outbreak was a public health emergency of international concern. ${ }^{3}$

ZIKV is an arthropod-borne neurotropic flavivirus that has the capacity to cause large-scale infectious outbreaks where the biological vector Aedes aegypti is endemic. 4 It is estimated that about $80 \%$ of the cases of acquired infections are asymptomatic and that the others have mild symptoms (sudden fever, arthralgia, maculopapular rash or non-purulent conjunctivitis) and are resolved within a few days to a week. In addition to vector transmission, sexual and maternal-fetal transmissions have been recognized. 5

Microcephaly is characterized by a cephalic perimeter below the expected for age and sex at birth caused by any factor that interferes with the proliferation and/or differentiation of nerve cells resulting in brain development disorders. The causes may be genetic or environmental, such as maternal exposure to viral agents, ethanol, drugs and radiation during gestation. 6

Microcephaly related to ZIKV infection is a relevant topic for the global public health ${ }^{2}$ and understanding its pathogenic mechanism is a challenge for the healthcare systems, and the available literature data are limited. ${ }^{7}$ This case report describes distinct neurological damage in monochorionic twins presumably caused by intrauterine infection by ZIKV.

\section{Description}

The monozygotic twins were born on February 26, 2016 at term, 37 weeks and 1 day of gestation, by cesarean section at a public hospital. The first twin weighed 2,362 $\mathrm{g}$ and had a cephalic perimeter (CP) of $26.0 \mathrm{~cm}$ at birth and the second twin weighed $2,506 \mathrm{~g}$ and a CP of $28.5 \mathrm{~cm}$. At birth, both presented Apgar scores of 10 in the first and fifth minutes. The 17-year-old mother was primigravida, resides in the Northeast of Brazil, Rh positive, with a normal body mass index, no family history of microcephaly and no history of exanthematic viral diseases, or exposure to drugs or radiation during her pregnancy. At the prenatal evaluation in the beginning of the third month of gestation, the TORCHS serologies (syphilis, toxoplasmosis, rubella, cytomegalovirus and HIV) were normal, with maternal immunity for rubella, whereas, three obstetric ultrasounds did not reveal any neurological abnormalities and but confirmed a monochorionic, diamniotic twin gestation.

Due to congenital microcephaly, the twins were taken to the Pediatric Outpatient Clinic at the Hospital Universitário (HU) (University Hospital) initiating the post-natal medical evaluation beginning 48 days after birth. At this service, the twins and the mother's (immune to rubella) results on the TORCHS serologies were normal. The twins' results on the ophthalmoscopy, x-ray of the chest, echocardiogram and electrocardiogram were normal. In the hearing assessment performed at one month and 24 days of life, the twins did not present alterations in the Otoacoustic Emission Test (ear test) and monitoring was recommended for early stimulation. At 2 months and 16 days after birth, they were evaluated by the Neuropediatrics Department of the University Hospital, confirming the diagnosis of severe microcephaly as they presented CPs below the mean of the three standard deviations for age and sex; the first twin had a CP of $30.5 \mathrm{~cm}$ and the second of $32.0 \mathrm{~cm}$. In addition, on the physical examination, the first twin presented signs of neuropsychomotor development delay (motor retardation). Both were taken to physiotherapy and they began rehabilitation twice a week.

In a subsequent neuropediatric evaluation at 5 months and 29 days of age, the mother reported myoclonic seizures in the first twin at a frequency of twice a week and Phenobarbital $(3 \mathrm{mg} / \mathrm{kg}$ as fractional dose) was prescribed. The neuropsychomotor development delay of the second twin (delayed motor and language) was evidenced at 7 months and 24 days of life.

The cranial ultrasound of the first twin showed a marked dilatation in the posterior horns and atria of the lateral ventricles; a significant reduction in the thickness of the cerebral parenchyma and corpus 
callosum and poor circumvolution; lenticular calcifications and subependymal cysts at the caudothalamic groove level. On the second twin, the examination revealed a slight reduction in the thickness of the cerebral parenchyma and the corpus callosum, subcortical and periventricular punctate calcifications were more evident on the right and septated cysts at the caudothalamic groove level. In both twins, the cranial computed tomography demonstrated microcephaly, sparse parenchymal calcifications in both hemispheres of subcortical predominance, gliosis and atrophy. The first twin presented hydrocephalus of supratentorial predominance (Figure 1). The right lateral ventricle of the second twin presented increased dimensions (Figure 2).

Due to the coincidence of the time of pregnancy and childbirth with the period of great circulation of ZIKV in the Northeast of Brazil and to the tomographic findings of the skulls in both twins in the period of intrauterine infection, and excluding TORCHS seropositivity, the children were clinic epidemiologically diagnosed with the presumed intrauterine ZIKV infection. Specific molecular and serological tests for ZIKV continued to be investigated. One year and five months after birth, the first twin had clinical signs of moderate to severe spastic tetra paresis and a CP of $38.0 \mathrm{~cm}$ and the second twin had predominant brachial spasticity and a $\mathrm{CP}$ of $38.8 \mathrm{~cm}$. Both were remained under follow-ups in a quarterly outpatient pediatric at the University Hospital.

\section{Figure 1}

Computed Tomography of the Cranial Scan of the first twin.

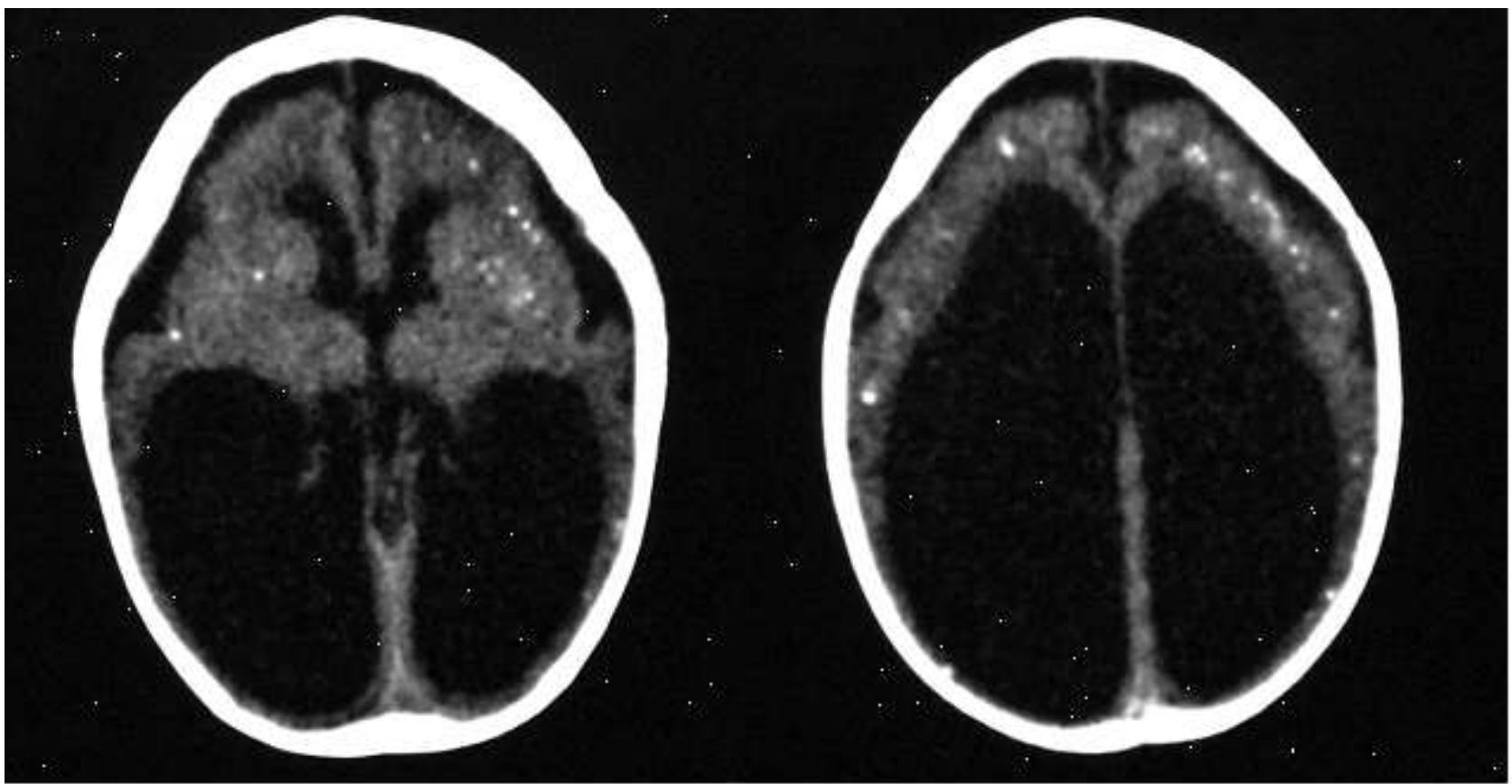

Computed tomography in the axial plane of the child's skull (first twin) demonstrating microcephaly presumably related to Zika virus with a marked increase in the dimensions of the ventricular system, reduction of cortical mantle thickness, and sparse, predominantly subcortical, parenchymal calcifications. 


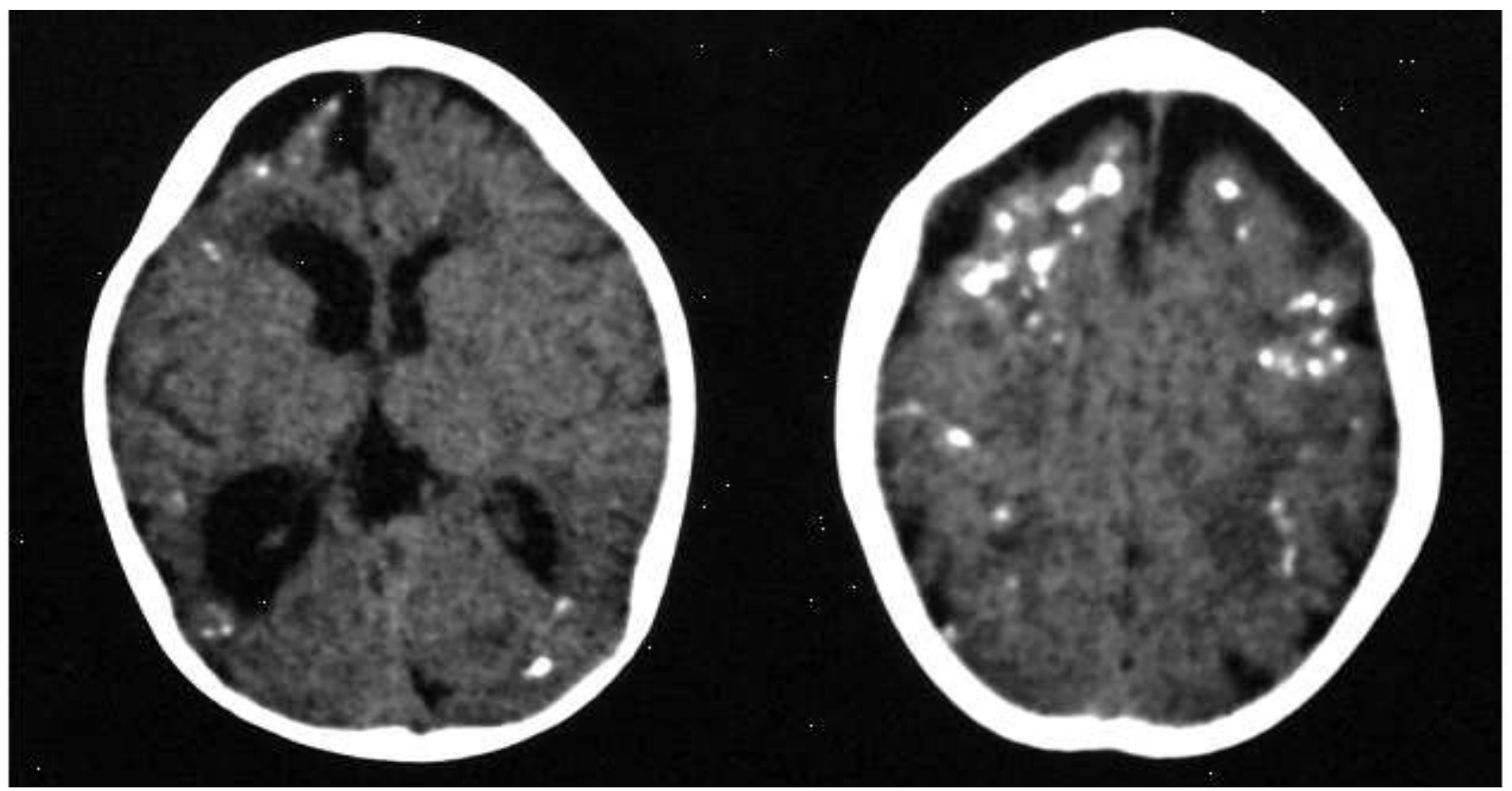

Computed tomography in the axial plane of the child's skull (second twin) demonstrating microcephaly presumably related to Zika virus with increased dimensions of the ventricular system, predominantly of the right lateral ventricle, and sparse, predominantly subcortical, parenchymal calcifications.

\section{Discussion}

ZIKV infection during the first trimester of gestation may impair neurogenesis, since this virus induces the death of the neurons and inhibits brain development and can result in severe brain malformations. ${ }^{8}$ Diagnosis of the infectious process is usually based on the history and clinical manifestations of the pregnant woman, as although molecular and serological tests for ZIKV exist, they are not commercially available. Neurological complications related to maternal-fetal infection by ZIKV can be detected during the prenatal period by obstetrical ultrasound and in the post-natal period by imaging the skull using transfontanel ultrasound and other diagnostic tests, such as computed tomography and magnetic resonance imaging. ${ }^{5}$ Neurological complications include microcephaly, cerebral calcifications, neuronal migration disorders, loss of brain tissue and dilation of the ventricular system. Intracranial changes are more severe in cases of fetal viral infection during the first gestational trimester and milder in the third trimester. ${ }^{9}$

The clinical diagnosis of microcephaly is based on a measurement of the head circumference at birth below two standard deviations of the mean for gestational age and sex. The Protocol on Health Care and Response to the Occurrence of Microcephaly (Version 3) recommends that, in full-term newborns, the head circumference reference values should be adopted for the definition of microcephaly that should be equal to or less than $31.5 \mathrm{~cm}$ for girls and $31.9 \mathrm{~cm}$ for boys. Microcephaly is considered severe in cases where the CP is less than three standard deviations of the mean, 10 as observed in both of these twins.

The measurement of the head circumference is made at the greatest circumference of the skull using a flexible, non-elastic measuring tape.

It is important to remember that, in cases of 
cranial abnormalities due to family, genetic or cranial shape during normal birth, the CP may be temporarily below the reference value for gestational age and sex Therefore, it is recommended to repeat the measurement one or more days after birth. ${ }^{9}$

Microcephaly is a clinical sign of complex and multifactorial etiology that may result from maternal diseases during pregnancy and from environmental teratogenic agents, among other causes that affect neurodevelopment and, therefore, influences the brain growth. ${ }^{9}$ Maternal infections, such as toxoplasmosis, cytomegalovirus, herpes virus, syphilis, rubella, HIV and ZIKV provoke alterations in the intrauterine brain development. Likewise, the exposure to drugs such as ethanol, irradiation, and maternal nutritional deficiencies can also alter normal brain development. 11

In addition to the neurological evaluation, newborns with microcephaly should be investigated for the presence of dysmorphic features and congenital anomalies affecting other organs including ophthalmologic, cardiac, renal, urinary tract disorders and among others. It is worth mentioning that children exposed to intrauterine ZIKV infections can present complex syndromes with multiple deficiencies as well as manifestations of development impairment detected later in life, such as learning deficits and inadequate social adjustment, without any evidence of anatomical neurological changes. 12

Alterations in the neuropsychomotor development and behavior may be accompanied by auditory and visual problems. Children from zero to three years of age with microcephaly, and with neuropsychomotor development impairment and associated effects benefit from the Early Stimulation Program. This program is a multiprofessional clinical-thera-

\section{References}

1. Brasil. Ministério da Saúde. Secretaria de vigilância em saúde. Monitoramento dos casos de dengue, febre de chikungunya e febre pelo vírus Zika até a Semana Epidemiológica 52, 2015. Bol Epidemiol. 2016; 47 (3): 110.

2. World Health Organization (WHO). Situation report: Zika Virus, Microcephaly and Guillain-Barré Syndrome, 26may 2016. Geneva: WHO Press; 2016. p.14

3. Teixeira MG, Costa CN, Oliveira WK De, Nunes ML, Rodrigues LC. The Epidemic of Zika Virus - Related Microcephaly in Brazil : Detection, Control, Etiology, and Future Scenarios. Am J Public Health. 2016; 106 (4): 601-5.

4. Minassian ML. Virus Zika: Crónica de una pandemia “impensada”. Rev Argent Microbiol. 2016; 48 (2): 97-9. peutic follow-up and intervention project that aims to stimulate children and increase their competences, dealing with stimulation that interferes in the improvement of the child's progress in favoring motor and cognitive development. 13

Developmental disorders, especially those associated to intellectual deficit, have a direct repercussion on the children's family quality of life and justify the need for monitoring mental health conditions and providing socio-emotional support for the parents. ${ }^{14}$ For this, it is necessary to rethink on public policies programs on the follow-ups of children with ZIKV-related to microcephaly, the social and emotional impact, the financial burden and the quality of life of the families involved with this problem. It is a challenge that must be faced with multiprofessional health teams prepared to evaluate and introduce interventions over time. 12

ZIKV infection was considered a public health emergency of national interest until May 2017, due to the sudden increase of children born with microcephaly and other neurological alterations during the outbreak that began in Brazil in November 2015. Despite the decrease of ZIKV cases reported, the possibility of further outbreaks cannot be ruled out. It is a great challenge for the healthcare system to understand the pathogenic mechanism of fetal microcephaly related to $\mathrm{ZIKV}, 7$ as well as to consider the incidence of the cofactors and the level of harm it caused. 4 This case report examines the occurrence of distinct neurological alterations in monochorionic twins presumably caused by intrauterine infection by ZIKV, which could indicate the hypothesis of the existence of intrinsic or viral load factors in the final process of this disease.
5. Staples JE, Dziuban EJ, Fischer M, Cragan JD, Rasmussen SA, Cannon MJ, Frey MT, Renquist CM, Lanciotti RS, Muñoz JL, Powers AM, Honein MA, Moore CA. Interim guidelines for the evaluation and testing of infants with possible congenital Zika Virus infection - United States, 2016. MMWR Morb Mortal Wkly Rep. 2016; 65 (3): 63-7.

6. Passemard S, Kaindl AM, Verloes A. Microcephaly. In: Handbook of clinical neurology, pediatric neurology part I. Elsevier BV, editor. London: Elsevier; 2013. p. 129-41.

7. Adibi JJ, Marques ETA, Cartus A, Beigi RH. Teratogenic effects of the Zika virus and the role of the placenta. Lancet. 2016; 387 (10027): 1587-90.

8. Garcez PP, Loiola EC, Costa RM, Higa LM, Trindade P, Delvecchio R. Zika virus impairs growth in human neurospheres and brain organoids. Science. 2016; 352 (6287): 816-18 
9. Nunes ML, Carlini CR, Marinowic D, Kalil Neto F, Fiori HH, Scotta MC, Zanella PLA, Soder RB, Costa JC Microcephaly and Zika virus: a clinical and epidemiological analysis of the current outbreak in Brazil. J Pediatr. 2016; 92 (3): 230-40.

10. Brasil. Ministério da Saúde. Secretaria de Atenção à Saúde. Protocolo de atenção à saúde e resposta à ocorrência de microcefalia. Brasília, 2016. [Acesso em 12 mai 2017] Disponível em: http://combateaedes.saude.gov.br/images/ sala-de-situacao/Protocolo_SAS_versao_3_atualizado.pdf

11. European Centre for Disease Prevention and Control (ECDC). Rapid risk assessment: microcephaly in Brazil potentially linked to the Zika virus epidemic. Stockholm, 2015. [Acesso em 12 mai 2017]. Disponível em: http://ecdc.europa.eu/en/http://ecdc.europa.eu/en/publications/Publications/zika-microcephaly-Brazil-rapid-riskassessment-Nov-2015

Received on June 30, 2017

Final version presented on October 13, 2017

Approved on February 23, 2018
12. Brunoni D, Blascovi-Assis SM, Osório AAC, Seabra AG, Amato CAH, Teixeira MCTV, Rocha MM, Carreiro LRR. Microcephaly and other Zika virus related events: the impact on children, families and health teams. Ciên Saúde Colet. 2016; 21 (10): 3297-302.

13. Brasil. Ministério da Saúde. Diretrizes de estimulação precoce. Crianças de zero a 3 anos com Atraso no Desenvolvimento Neuropsicomotor Decorrente de Microcefalia. Brasília: 2016. [Acesso em 15 mai 2017]. Disponível em: http://www.saude.go.gov.br/public/media/ ZgUINSpZiwmbr3/20066922000062091226.pdf

14. Favero-Nunes MA, Santos MA. Itinerário terapêutico percorrido por mães de crianças com transtorno autístico. Psicol Reflex e Crít. 2010; 23(2): 208-21. 